\title{
Characterisation of the damaging micromechanisms in a pearlitic ductile cast iron and damage assessment by acoustic emission testing
}

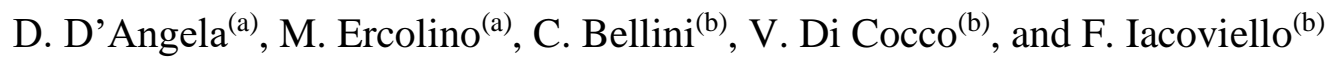 \\ (a) School of Engineering, University of Greenwich, London, UK \\ (b) Department of Civil and Mechanical Engineering, University of Cassino and Southern \\ Lazio, Cassino, Italy
}

\begin{abstract}
The damaging micromechanisms in a pearlitic (EN-GJS700-2) Ductile Cast Iron (DCI) are investigated by means of Scanning Electron Microscope (SEM) analysis and Acoustic Emission (AE) testing. Monotonic uniaxial tensile tests are performed on microtensile specimens under strain control. SEM analysis is applied under in-situ conditions by means of a tensile holder. The multiple damaging micromechanisms are identified, and their evolution along with the mechanical response is characterised. The traditional AE features are found to be qualitatively correlated to the onset of the fracture damage over the elastic behaviour. The Information Entropy of the AEs evaluated according to both Shannon and Kullback-Leibler formulations is proven to be well correlated to the ongoing damage, and the incipient failure. Tentative failure criteria are finally proposed. The assessment approach is found to be promising for structural health monitoring purposes.
\end{abstract}

KEYWORDS: Ductile Cast Iron (DCI); Scanning Electron Microscope (SEM); Acoustic Emissions (AEs); Shannon Entropy; Structural Health Monitoring

\section{INTRODUCTION}

In the last decades, the industry encouraged the experimental investigation of Ductile Cast Irons (DCIs) [1]. These materials are commonly used for a variety of critical engineering systems such as pipelines and wind turbines [2,3]. DCIs were obtained in the '40s by adding different elements, such as magnesium or cerium, during the preparation/treatment of cast 
irons. The addition produced nodular graphite elements embedded within the iron matrix, instead of the elongated flakes (lamellae), typical of grey cast irons. Similar results had already been achieved by annealing white irons; however, this treatment was extremely difficult and expensive. DCIs are comparable to structural steels in terms of both strength and ductility, as well as they present the good castability of grey cast irons [4,5]. The matrix of DCIs governs the main mechanical properties of the material such as the strength, as well as it defines the name of the DCI. The graphite nodules were considered in the past as mechanical voids, and the matrix-nodule debonding was assumed as the primary mechanism involving the nodules [6,7]. Recent studies (e.g., [2,8,9]) proved that the damage evolution of DCIs is quite more complex. The damaging micromechanisms might either start within the nodules or affect them in the early stages of deterioration. The classical matrix-nodule debonding behaviour was rarely observed in ferritic DCIs, and multiple damaging micromechanisms were found to be more significant [4,10]. Figure 1 shows the (a) undeformed, and (b) deformed condition of a graphite nodule embedded within a ferritic DCI subjected to tension loading $[4,11]$. The recently identified onion-like and disgregation mechanisms are highlighted in Figure 1.b. The onionlike mechanism defines the initiation and propagation of cracks between the nodule core and the external crown according to the fibrous shape of the onions. The disgregation mechanisms involve cracking initiation and propagation in the central part of the nodules, with a potential disgregation of the nodule under plastic deformation. The microstructure of the matrix influences the occurrence of such mechanisms; however, the microstructure does not affect their characteristic features (e.g., the morphology of the fracture surfaces), which might depend on the nonhomogeneous distribution of the mechanical properties within the nodules. A step forward is needed to enhance the knowledge of these phenomena. The features of the damaging micromechanisms occurring in pearlitic DCIs have not been identified yet, as well as the initiation/evolution of the damage along with the mechanical response is not clear.
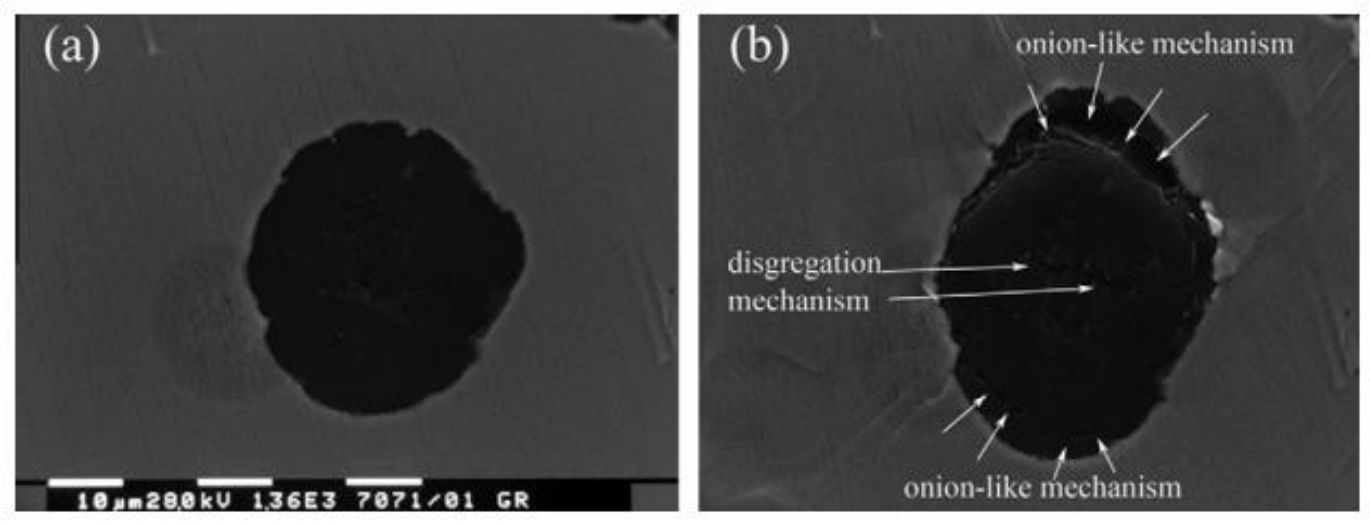
Figure 1. Damage micromecanisms identified in ferritic DCIs (EN GJS350-22) at following $\sigma$

$$
\text { [MPa] }-\varepsilon[\%]: \text { (a) } 0-0 \text {, (b) } 470-14 \text { [4]. }
$$

Acoustic Emission (AE) testing represents the state-of-the-art for non-destructive evaluation of damage in structural components [12,13]. This technique has been used in several engineering systems affected by fracture and fatigue damage, such as bridges [14], pipelines [15], and industrial plants [16]. AE testing is based on the phenomena of the localised stressenergy releases caused by microdamage within solids. Such releases generate elastic (acoustic) waves with low intensity and relatively high frequency, namely the Acoustic Emissions (AEs). The AEs propagate within the components, also interacting with their structural discontinuities. The AE activity can be detected by specific sensors attached to the monitored elements (or to the components connected to them). The AEs can be analysed in real-time as well as they can be post-processed in order to characterise the state-of-health of the monitored systems. Several studies provide approaches/methods to analyse the $\mathrm{AE}$ data for the damage assessment of structures (e.g., [17-21]). AE testing has been increasingly applied in automated monitoring processes, especially for infrastructural systems [13,22-24]. A schematic application of the technique is shown in Figure 2.a (by MISTRAS Limited). The evolution of the main features of the AEs (namely $A E$ features, Figure 2.b) is potentially correlated to the damage, even though a more refined analysis typically allows a more robust assessment (e.g., [17,25,26]).

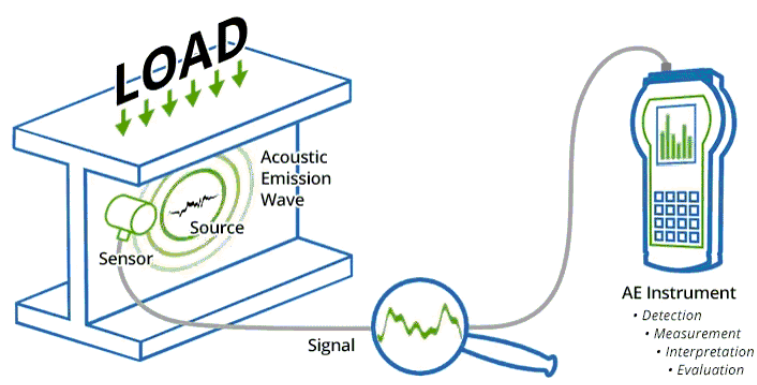

(a)

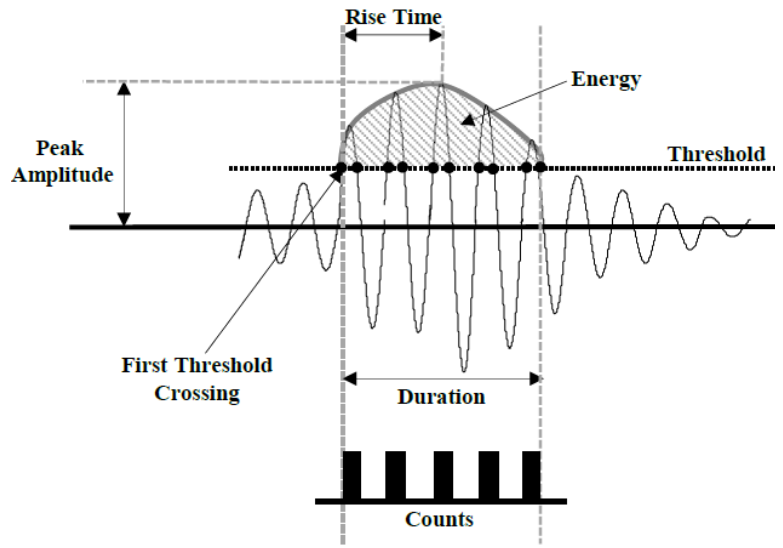

(b)

Figure 2. AE testing: (a) technique application scheme (by MISTRAS Limited), and (b) main AE features [27].

Several studies used AE testing for the damage identification in various metals and alloys (e.g., [21,26,28,28-30]). However, very few studies applied AE testing for evaluation of damage in 
DCIs. Carpenter and Zhu [31] investigated the damage correlations between the uniaxial compressive response of ferritic DCIs and the related AE activity. They identified relationships capable of estimating the fracture toughness, as well as they correlated the average size of the graphite nodules to the AEs. Sjögren and Svensson [32] analysed the AEs generated by the response of pearlitic DCIs. They proved that the AE activity can be descriptive of the damage stages, especially within the elastic response range. More recently, Kietov et al [33] investigated the damage evolution in ferritic DCIs by means of AE testing, also considering high-strength steels for comparison purposes. They performed dynamic tests on Charpy Vnotch specimens with and without fatigue pre-crack at various temperatures. The AE activity was found to be associated with cleavage fracture, and a linear correlation was defined between the fracture area and the AE Amplitude. The AE activity was also related to the onset of the plastic response. The same authors [34] performed both tensile and three-point bending tests on ferritic DCIs at quasi-static and dynamic rates, also varying the temperature. The onset of the plastic response was confirmed to be correlated to significant AE activity, and simultaneous peaks of acoustic activity were detected just after the yielding. Among the latest AE analysis methods, the evaluation of Information Entropy of the AE data (namely, AE Entropy or Acoustic Entropy) was recently proven to be promising for fatigue and fracture assessment in metals. Kahirdeh and Khonsari [25,35] found that that the AE Entropy, evaluated by using the Shannon formulation [36], can be a more reliable predictor of the fatigue and fracture damage than the traditional AE features. A relative measure of Entropy based on the Kullback-Leibler formulation [37] was also investigated in [24,26] showing promising results. This approach was also applied for damage monitoring purposes; however, a more robust application should still be defined [24,26,38,39].

This paper attempts to enhance the understanding of the damaging micromechanisms occurring in (pearlitic) DCIs, providing insights into the damage assessment by means of AE testing. The multiple damaging micromechanisms are identified by using in-situ SEM analysis. The damage evolution is associated with AE activity. Basic AE analysis is performed in order to define qualitative damage correlations. The Information Entropy of the AE data is evaluated using both Shannon and Kullback-Leibler formulations to establish damage criteria promisingly applicable to structural health monitoring. 


\section{MATERIAL AND EXPERIMENTAL PROCEDURE}

Three monotonic uniaxial tensile tests were performed on flat microtensile specimens made of a pearlitic DCI (EN GJS700-2), with nominal strength $\sigma_{u}$ equal to $700 \mathrm{MPa}$. The graphite elements of the tested specimens were characterised by a nodularity higher than $85 \%$, having a volume fraction equal to $9 \div 10 \%$. The chemical composition is reported in Table 1 , and the geometry of the specimens is shown in Figure 3. The microtensile specimens were extracted by a cylindrical billet (diameter equal to $80 \mathrm{~mm}$ ); they were ground and polished. The tests were performed through strain control, with a constant strain rate equal to $0.2 \mathrm{~s}^{-1}$. A step-bystep testing procedure was used to allow the periodic SEM analysis of the specimen under insitu conditions. The tension was applied and kept on the specimens using a tensile holder $[2,4,10]$. The deformation of the specimens was controlled by a Linear Variable Differential Transformer (LVDT). Two miniature load cells ( $10 \mathrm{kN}$ each) were used to measure the applied load. The tensile holder and the whole testing equipment are shown in Figure 4 [10].

Table 1. Chemical composition in $w t \%$ for pearlitic DCI (EN GJS700-2).

\begin{tabular}{ccccccccccc}
\hline $\mathbf{C}$ & $\mathbf{S i}$ & $\mathbf{M n}$ & $\mathbf{S}$ & $\mathbf{P}$ & $\mathbf{C u}$ & $\mathbf{M o}$ & $\mathbf{N i}$ & $\mathbf{C r}$ & $\mathbf{M g}$ & $\mathbf{S n}$ \\
\hline 3.59 & 2.65 & 0.19 & 0.012 & 0.028 & 0.004 & 0.004 & 0.029 & 0.061 & 0.060 & 0.098 \\
\hline
\end{tabular}

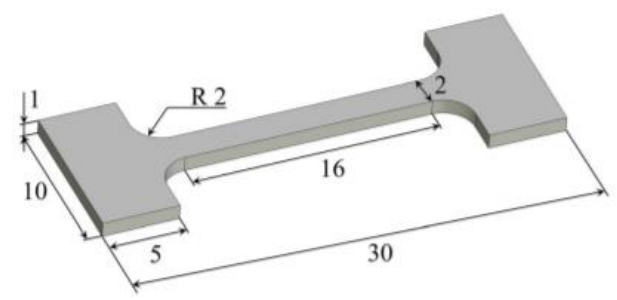

Figure 3. Geometry of the microtensile specimens (in $\mathrm{mm}$ ). 


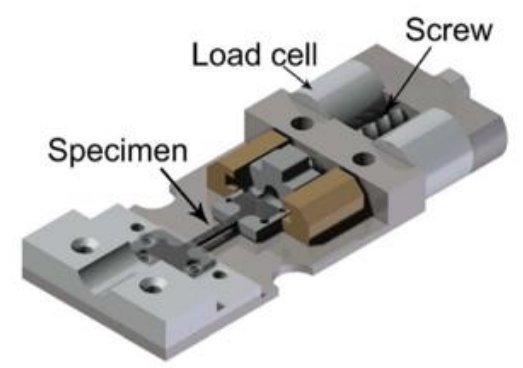

(a)

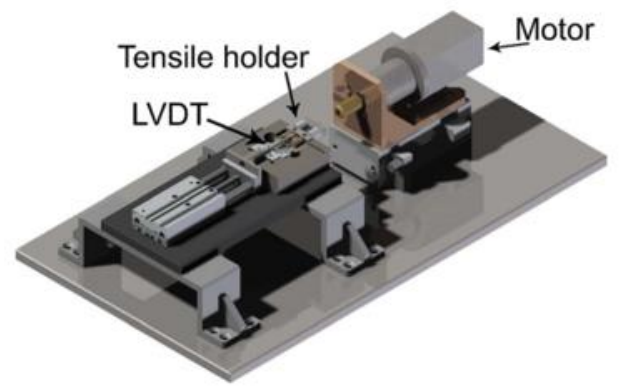

(b)

Figure 4. Tensile testing equipment: (a) detail of tensile holder, and (b) whole testing machine [10].

AE testing was performed along with the tensile testing according to the parameter-based approach [13]. The tensile testing procedure was time-continuous during AE testing. The whole AE testing equipment was produced by MISTRAS Limited (UK), and it was already used in [26]. Two 1283 USB AE Node systems were simultaneously used to process and store the AE activity. The AEs were detected by two PK15I sensors, i.e., pre-amplified ultra-low noise sensors having a resonance frequency equal to $150 \mathrm{kHz}$, and operating within $100 \div 450$ $\mathrm{kHz}$. The software $A E$ win $^{\mathrm{TM}}$ was used to process, visualise, and store the AEs in real-time. The sensors were coupled/bonded to the fixed parts of the tensile machine by means of a thin layer of silicon (Loctite 595) [18,21]. Figure 5 shows the AE system layout and testing set-up. The sensor 1 was the closest to the specimen to detect the genuine signals due to the specimen damage process even though the sensor was not directly located on the specimen. The sensor 2 was located on the support of the tensile machine in order to identify the features of the noise disturbance due to the testing equipment (e.g., vibrations transferred from the motor supports to the machine supports). The reliability of the sensor coupling was checked by Pencil Lead Break (PLB) test prior to the main tests [21,26]. The AE Amplitude threshold was set equal to 45dB; the Peak Definition Time (PDT), the Hit Definition Time (HDT), and the Hit Lockout Time (HLT) were set equal to 200, 800, and $1000 \mu$ s [18,26]. A $50 \mathrm{kHz}$ high-pass filter was applied as suggested in the literature [18], even though the sensors are mainly operating within $100 \div 450 \mathrm{kHz}$.

Microtensile low-carbon steel specimens were also tested according to the same procedure used for the pearlitic DCI. This was aimed at identifying the different features/trends of the AEs sourced by the simpler damaging micromechanism affecting low-carbon steels. 


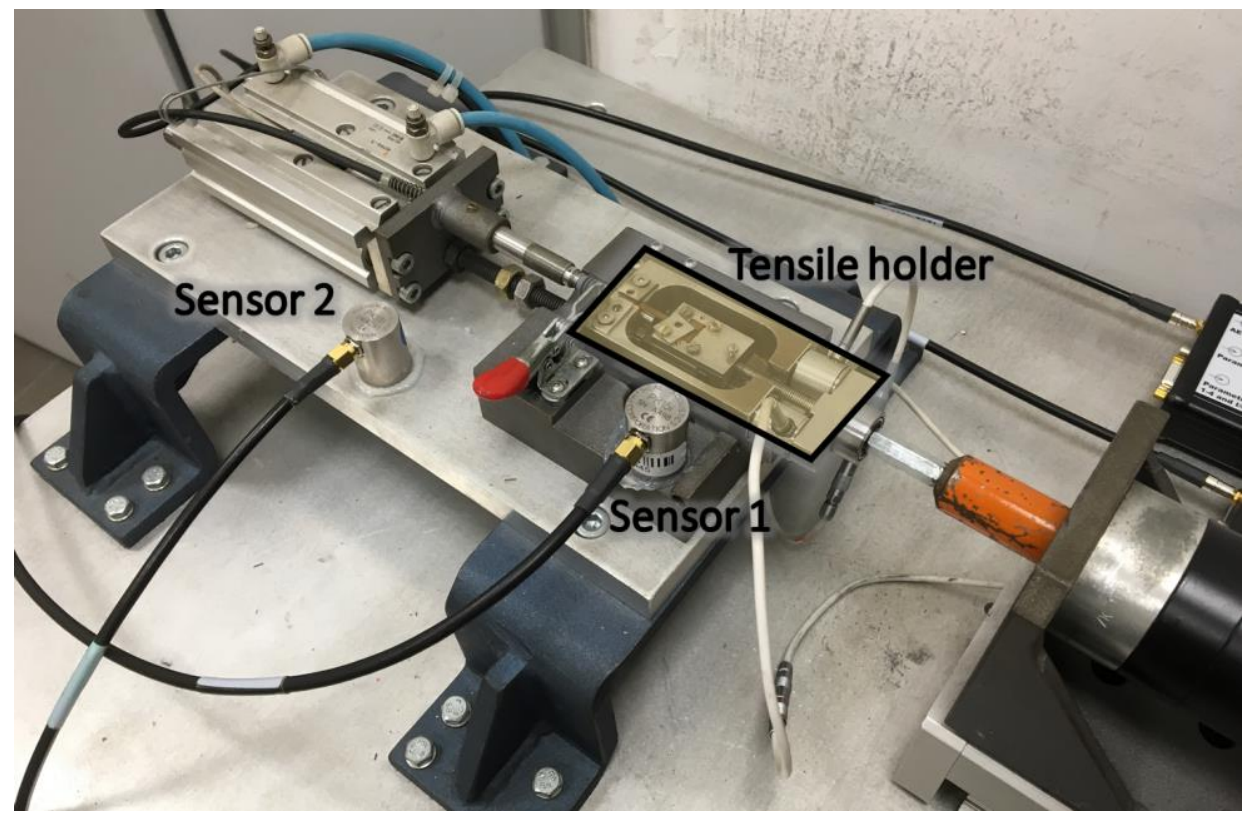

Figure 5. Testing set-up with detail on sensors' location.

\section{AE DATA ANALYSIS}

Both historical and correlation plots were applied to analyse the AEs. The Information Entropy of the AE data was computed according to both Shannon and Kullback-Leibler formulations, i.e., $S_{E}$ and $S_{E, r}$ in Equation (1) and (2), respectively [24,38]. The probability mass distribution vector $\boldsymbol{p}_{\boldsymbol{i}}$ is defined in Equation (3), where $n_{i}$ and $\Sigma n_{i}$ define Counts and cumulative Counts. The Shannon formulation implicitly assumes that each individual AE signal does not affect the following one. On the contrary, Kullback-Leibler Entropy considers the conditional probability between the current event and the previous one $\left(p_{i} \mid p_{i-1}\right)$ to compute a relative measure of Entropy. The cumulative Entropy over time was calculated for both formulations defining $\Sigma S_{E}$ and $\Sigma S_{E, r}$.

$$
\begin{aligned}
& \mathrm{S}_{\mathrm{E}}=-\sum_{\mathrm{i}=1}^{\mathrm{N}} \mathrm{p}_{\mathrm{i}} \log _{2}\left(\mathrm{p}_{\mathrm{i}}\right) \\
& \mathrm{S}_{\mathrm{E}, \mathrm{r}}=\mathrm{S}_{\mathrm{E}}\left(\mathrm{p}_{\mathrm{i}} \mid \mathrm{p}_{\mathrm{i}-1}\right)=-\sum_{\mathrm{i}=1}^{\mathrm{N}} \mathrm{p}_{\mathrm{i}} \log _{2}\left(\frac{\mathrm{p}_{\mathrm{i}}}{\mathrm{p}_{\mathrm{i}-1}}\right) \\
& \mathbf{p}_{\mathrm{i}}=\left\{\frac{\mathrm{n}_{1}}{\Sigma \mathrm{n}_{\mathrm{i}}} ; \frac{\mathrm{n}_{2}}{\sum \mathrm{n}_{\mathrm{i}}} ; \ldots ; \frac{\mathrm{n}_{\mathrm{i}}}{\sum \mathrm{n}_{\mathrm{i}}}\right\} ; \sum \mathrm{n}_{\mathrm{i}}=\sum_{\mathrm{k}=1}^{\mathrm{i}} \mathrm{n}_{\mathrm{k}}
\end{aligned}
$$




\section{RESULTS}

\section{Mechanical response and damaging micromechanisms}

An approximately linear elastic behaviour was observed in all specimens up to engineering stress equal to about $560 \div 600 \mathrm{MPa}\left(\sigma / \sigma_{u}=0.80 \div 0.85\right)$, corresponding to a strain equal to about $6 \%$. A gradual yielding knee was observed after the linear elastic limit, after which the material exhibited a reduced post-elastic stiffness. The failure occurred just after the ultimate strength was reached (average stress equal to $750 \mathrm{MPa}$ and strain about $10 \%$ ), or following a short softening branch (stress about $675 \mathrm{MPa}$ and strain about $11 \div 12 \%$ )

A number of 13 graphite nodules in a representative sample were considered for the SEM analysis of the damaging micromechanisms (Figure 6).

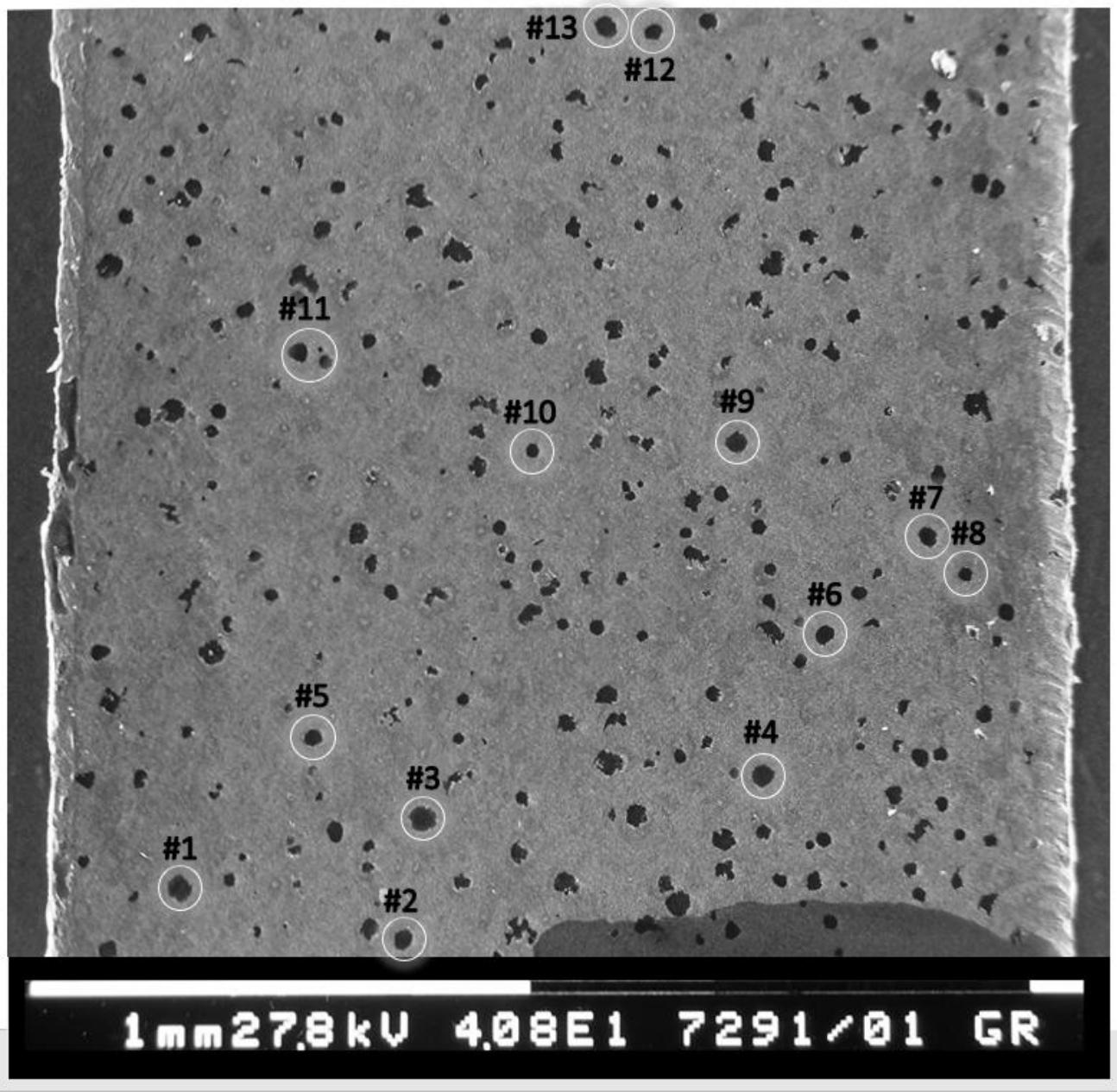

Figure 6. Graphite nodules considered for SEM analysis. 
Three elementary mechanisms were identified: (a) onion-like (Figure 7), (b) matrix-nodule debonding (Figure 8), and (c) disgregation (Figure 8). In the case of onion-like mechanism, multiple cracks initiated within the graphite nodules between the core and the nodule-matrix interface (Figure 7.b). Their onset was observed prior to the elastic limit even though they presented reduced width at this stage. The crack surfaces initiated and propagated following an approximately circular crown in the aforementioned area, often with a shape similar to the close nodule-matrix interface segment (Figure 7.b-d). The multiple cracks extended along with the strain deformation increase, tending to connect among them and form macrocracks (Figure 7.c) with a shape similar to onion layers (fibrous shape). The crack widths significantly increased when the material response became plastic.

(a)
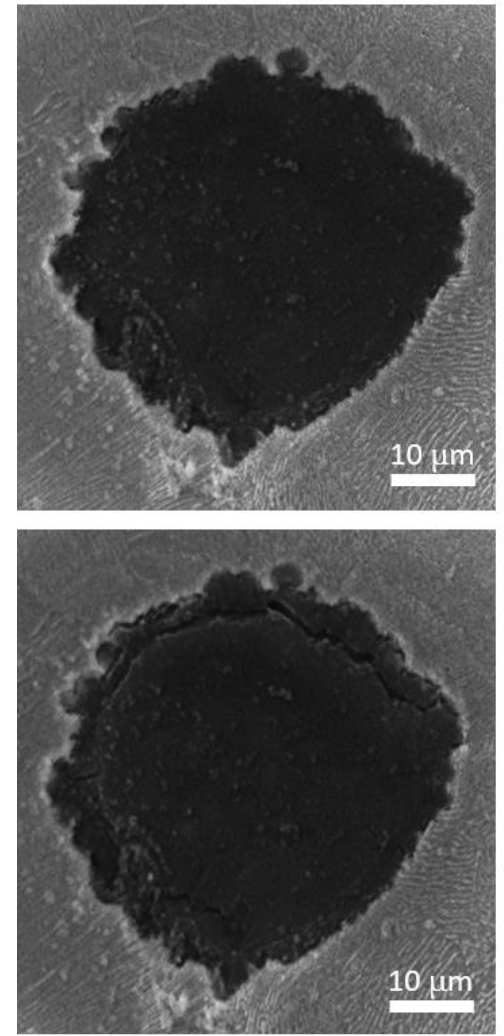

(c) (b)
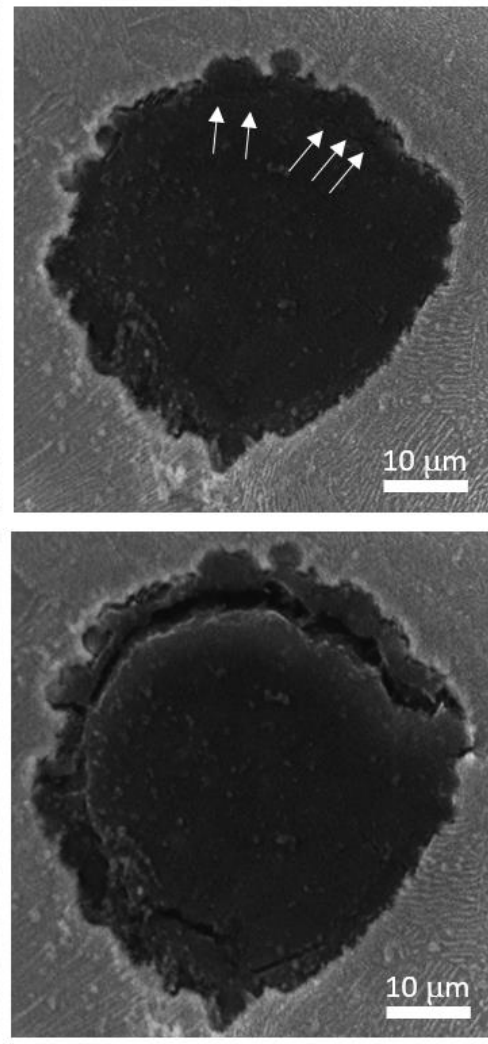

(d)

Figure 7. SEM analysis of the onion-like damaging micromechanism occurring in nodule \#4 at following $\sigma[\mathrm{MPa}]-\varepsilon$ [\%]: (a) $0-0$, (b) 595.2 - 4.5, (c) 696.3 - 8.0, and (d) $781.1-13.1$ (failure). The cracking initiation is highlighted with arrows.

The matrix-debonding mechanism occurred in most of the considered nodules (Figure 8.d) at the elastic stage. As for the onion-like cracks, the debonding width significantly increased when 
the plastic deformation occurred. In some cases, the same cracks presented both debonding and onion-like mechanisms, but there were few cases in which the deboning was the only mechanisms affecting a single nodule. The disgregation mechanism was characterised by the onset of microcracking within the core of the nodules. Such cracks were orientated suborthogonally to the direction of the applied tension (Figure 8.b) in many cases. The width increased along with the deformation evolution, especially after the elastic limit (Figure 8.c). This mechanism was often developed after at least one of the other mechanisms. Figure 9 shows the onset of the three damaging micromechanisms over the considered cases. The crack formation was also exhibited by the pearlitic matrix at relatively high levels of stress (e.g., about $600 \mathrm{MPa}$ ). Such cracks propagated along with the deformation increase, and their coalescence led to the specimen failure.

(a)
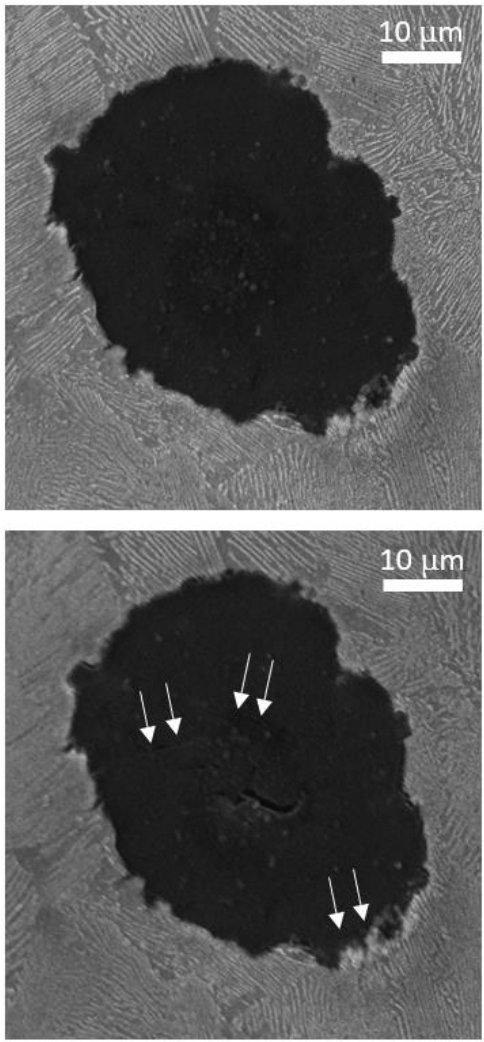

(c) (b)
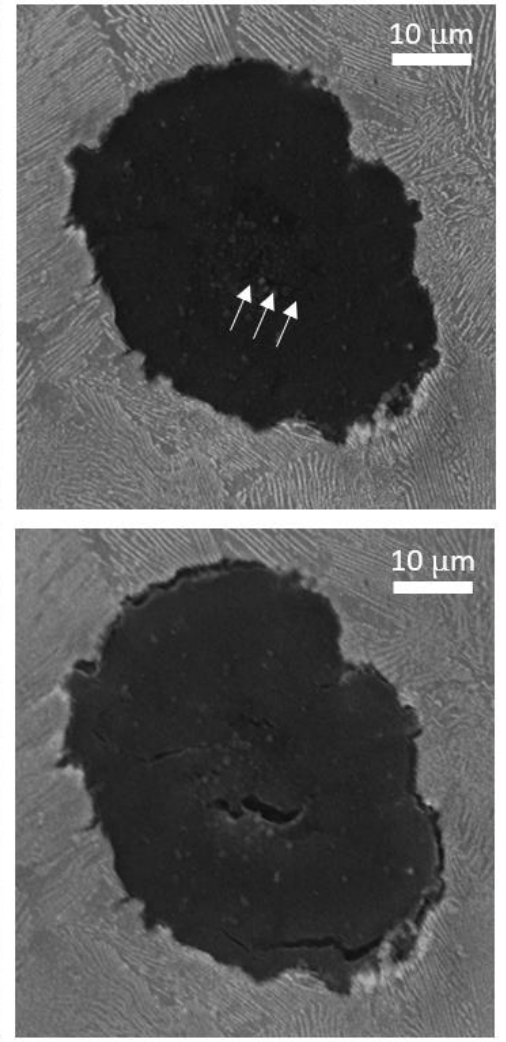

(d)

Figure 8. SEM analysis of mixed damaging micromechanisms occurring in nodule \#13 (i.e., onion-like, matrix-nodule debonding, and disgregation) at following $\sigma[\mathrm{MPa}]-\varepsilon[\%]$ : (a) $0-$ 0 , (b) $489.6-3.5$, (c) $694.3-7.2$, and (d) $781.1-13.1$ (failure). The cracking initiation is highlighted with arrows. 


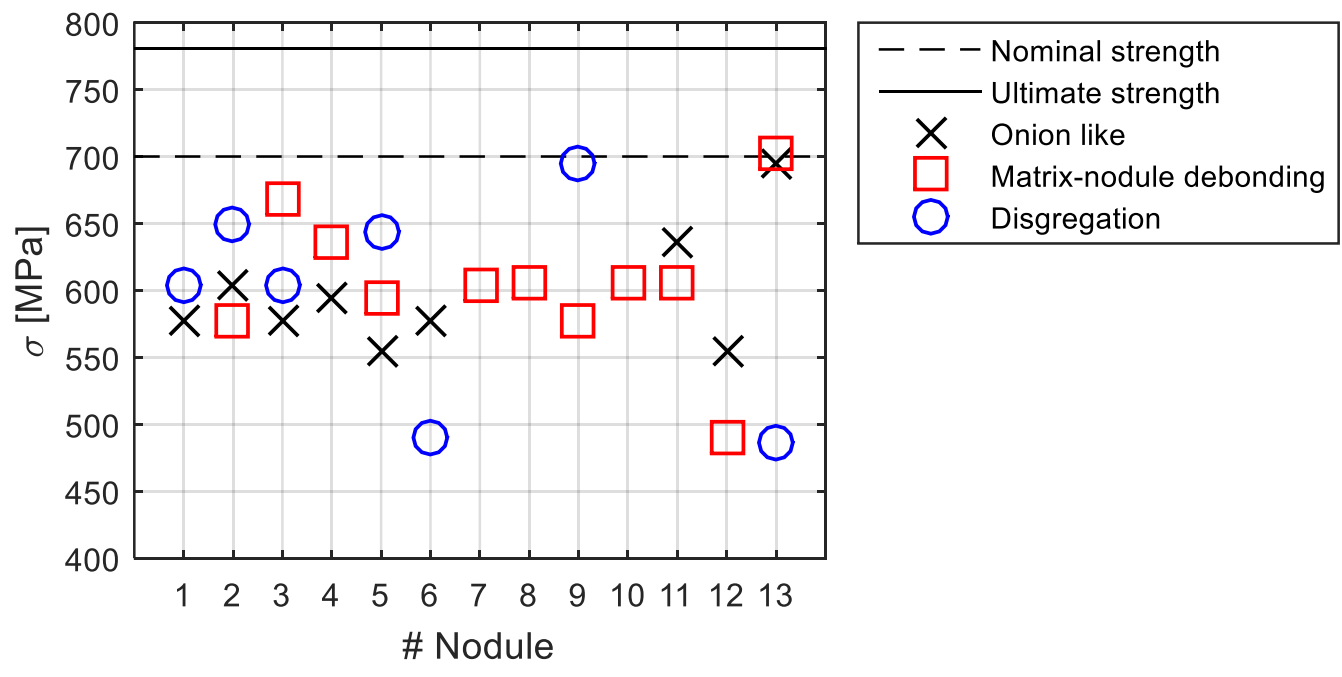

Figure 9. Onset of the damaging micromechanisms in the considered nodules.

\section{AE features}

The sensor 1 (Figure 5) detected significant AE activity during the testing having an episodic character (i.e., a series of distinct time-discontinuous stages of AE activities with peculiar features). The tests phases with high AE activity were very similar in all the performed tests by giving a preliminary confirmation of the reliability for the damage evolution assessment. The sensor 2 detected a minimal AE activity with quite different features in the performed tests. Such evidence demonstrates that the sensors are capable of minimising the noise disturbance caused by the mechanical equipment (sensor 2), as well as they can detect the data related to the actual damage (sensor 1). The AEs are presented in this section for three representative tests (tests 1,2, and 3) by only considering sensor 1 . Similar results were observed for all other tests and they are not presented for the sake of brevity. Figure 10 shows the time evolution of the engineering stress $\sigma$ along with the main historical plots of the AE activity. In particular, the scattered values of (logarithmic) Counts $\log _{10} N$, (logarithmic) Energy $\log _{10} E$, and the (peak) Amplitude A are plotted for all the single AE events (Figure 2.b). The AE activity over time showed some similarities among the different tests, identifying three stages. (1) AE activity was detected in the very early stage of the elastic response (i.e., between $10 \mathrm{~s}$ and 20 s, with $\sigma / \sigma_{u}$ lower than 0.4 ) for both test 1 and 2. (2) AE activity was detected prior to the elastic limit and the yielding point (i.e., between $37 \mathrm{~s}$ and $52 \mathrm{~s}$, with $\sigma / \sigma_{u}$ between 0.80 and 1.0) for all tests. (3) Abrupt AE activity was detected just prior to the failure for all tests. Therefore, stages 1,2 , and 3 were defined by the following stress intervals: $\sigma / \sigma_{u} \leq 0.80,0.80<\sigma / \sigma_{u} \leq 1.00$, and $\sigma / \sigma_{u}>1$. Some activity was also detected significantly earlier than the failure (after the yielding) 
in the case of test 1 . Stages 1 and 2 presented similar features, which are significantly different from the ones in stage 3. During test 1 , the activity related to stage 1 (117 events) was more copious than in stage 2 (35 events), also having larger Counts, Energy, and Amplitude. An opposite trend was observed in test 2 (35 events for stage 1 and 179 for stage 2). No activity was detected over stage 1 of test 3, but a significant activity occurred over stage 2 (90 events). All tests have a very similar number of events occurring within stage 3 (between 11 and 15). Considering all the tests, $61 \%$ of the whole activity was detected over stage 2 (initiation of the damage within the graphite nodules).

(a)

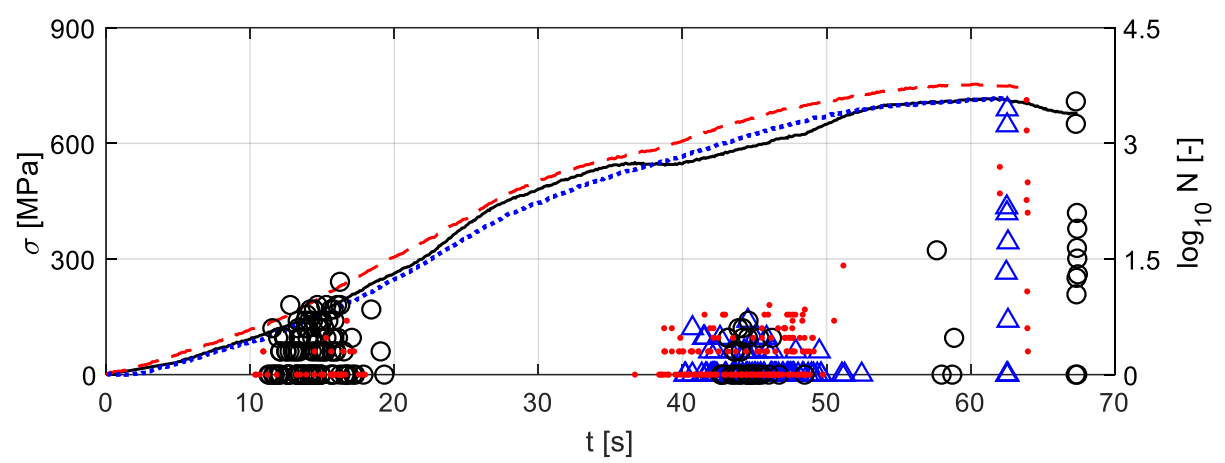

(b)

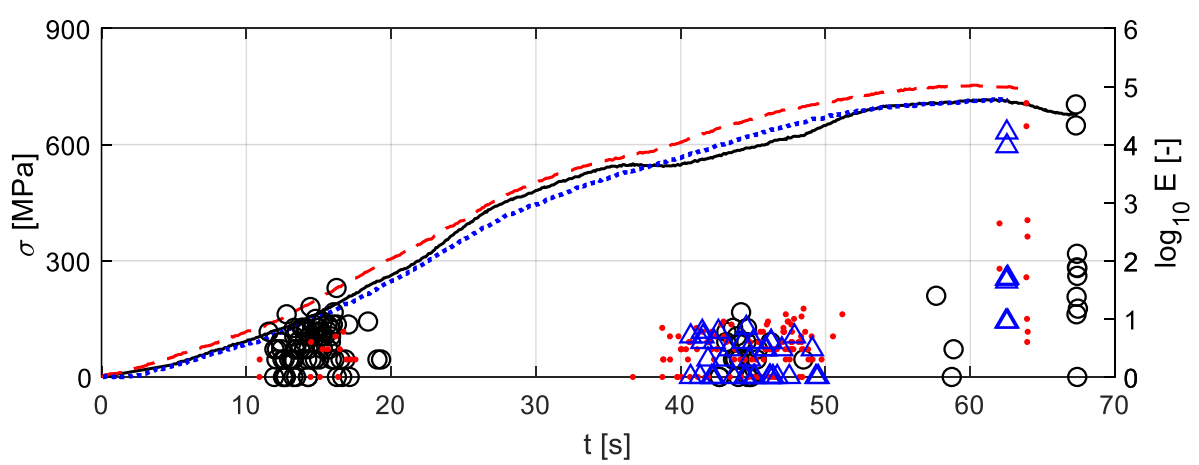

(c)

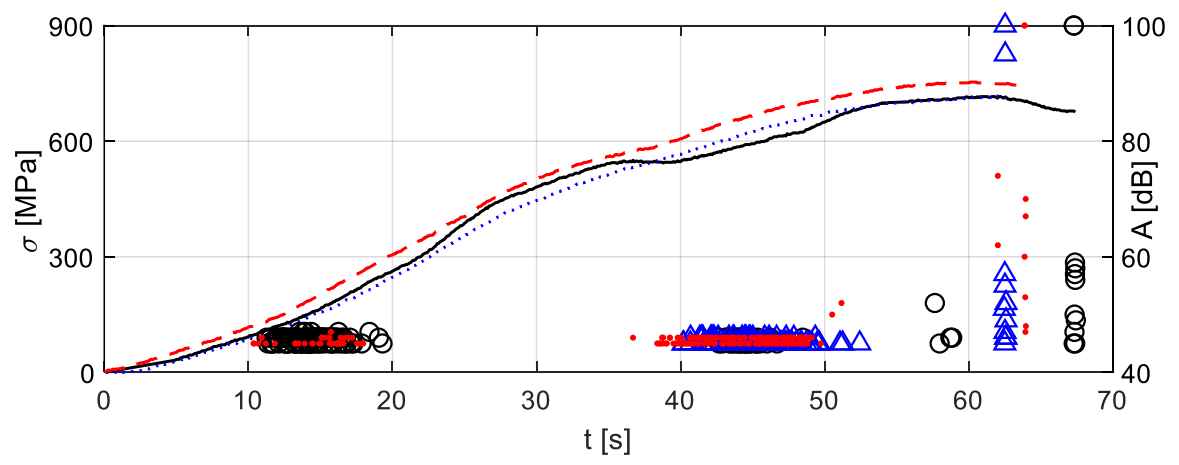

$\sigma_{1}---\sigma_{2} \cdots \cdots \cdots \sigma_{3} \quad \bigcirc \quad$ AE feature ${ }_{1} \quad . \quad$ AE feature ${ }_{2} \quad \triangle \quad$ AE feature ${ }_{3}$

Figure 10. Engineering Stress $\sigma$ vs Time $t$ (left axis) and AE features vs Time $t$ (right axis), considering (a) logarithmic Counts $\log _{10} N$, (b) logarithmic Energy $\log _{10} E$, and (c) Amplitude 
Figure 11 shows the correlation plots by considering the entirety of the AE data in the performed tests. Overall, stage 1 exhibited fewer events than stage 2, but lower values of the AE features. The activity related to both stages is quite low in terms of Energy as well as other features if compared to the one occurring in stage 3, where all features have significantly high values. Stage 3 has a large data scattering if compared to the other stages, and stage 2 has a scattering slightly lower than stage 1, as it can be seen in Figure 11. The features of the AEs do not have a clear pattern at the three identified stages, and the correlation analysis does not seem to be able to detect the damage in the framework of health monitoring.

(a)
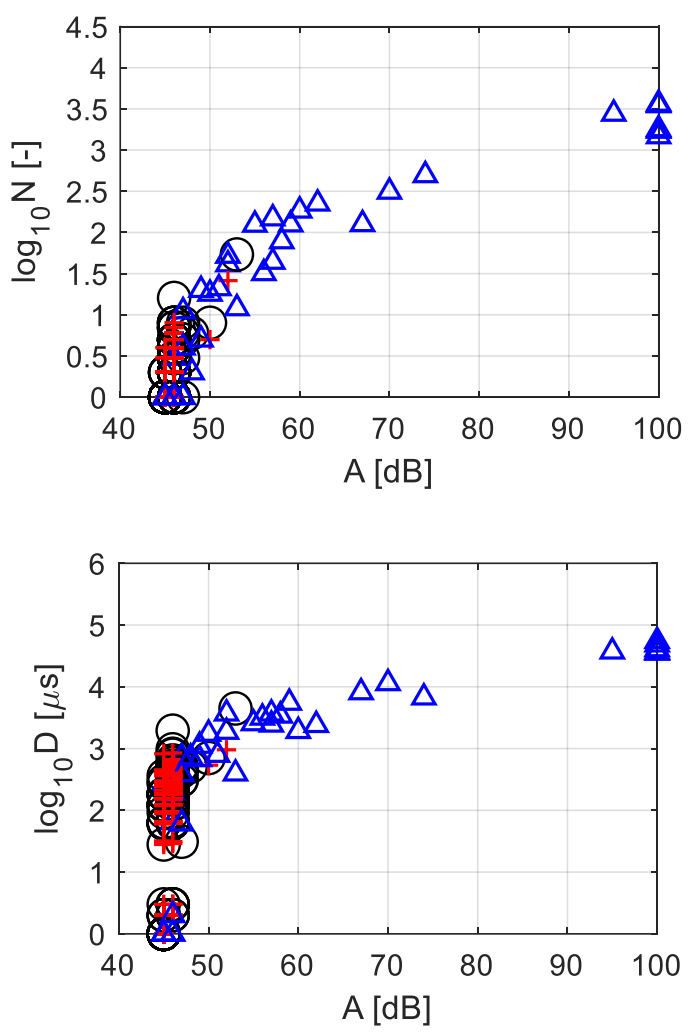

(c) (b)
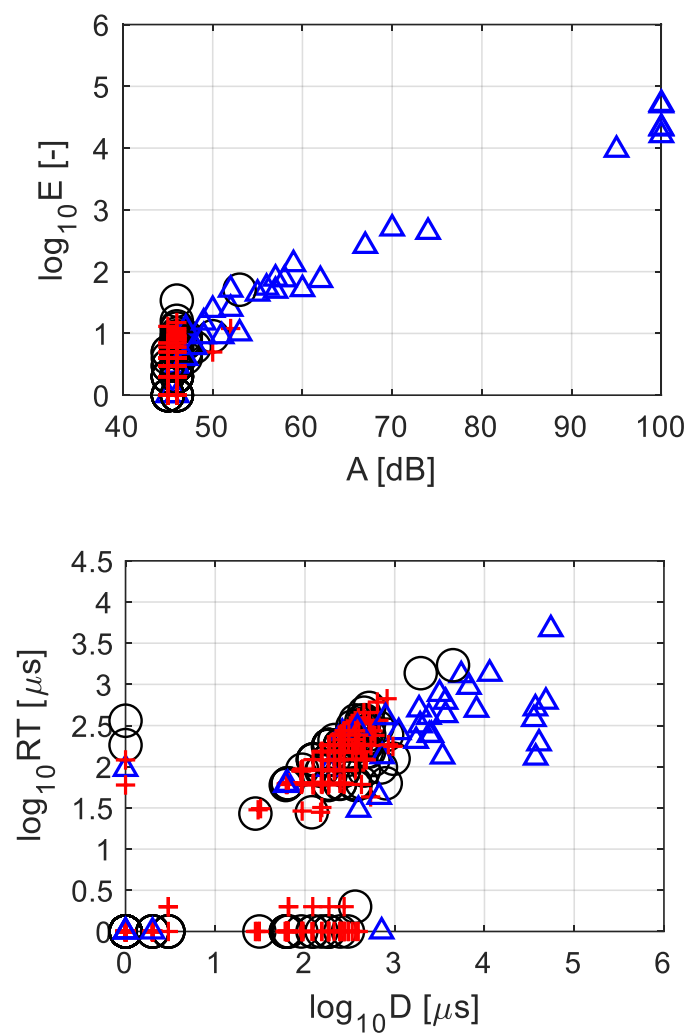

(d)

stage $1+$ stage $2 \Delta$ stage 3

Figure 11. Correlation plots among AE features considering all tests: (a) logarithmic Counts $\log _{10} N$ vs Amplitude $A$, (b) logarithmic Energy $\log _{10} E$ vs Amplitude $A$, (c) logarithmic Duration $\log _{10} D$ vs Amplitude $A$, and (d) logarithmic Rise Time $\log _{10} R T$ vs logarithmic Duration $\log _{10} D$. 
Low-carbon steel specimens exhibited AE activity with features significantly different from the pearlitic DCI ones, as it was expected. In particular, a copious time-continuous activity was observed from the beginning of the test up to the failure of the specimen. This activity had Energy $E$ significantly lower than the one related to the pearlitic DCIs, as it is shown in Figure 12. A similar trend was observed considering the other AE features, which are not shown in the paper for the sake of brevity. The use of a more refined approach for AE processing is evidenced by the results of the basic analysis of the AE features.

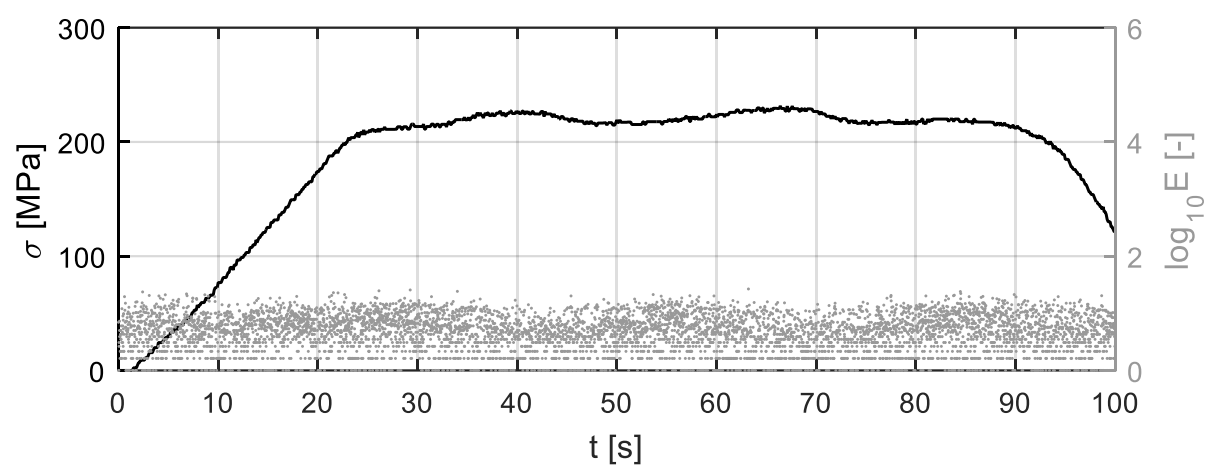

Figure 12 Engineering Stress $\sigma$ vs Time $t$ (left axis) and logarithmic Energy $\log _{10} E$ vs Time $t$ (right axis) for tests on low-carbon steel.

\section{AE Entropy}

Figure 13 shows logarithmic both the cumulative Shannon (a) and Kullback-Leibler Entropy (b) along with the engineering stress $\sigma$. The curves of the different tests show a similar shape, with particular regard to Shannon Entropy. The late detection of the AEs related to test 3 (i.e., no activity detected over stage 1) caused an Entropy curve only defined from stage 2. However, this curve has the same trend as the others, and it reaches a very similar value (and slope) at the incipient failure. The slope of the Shannon Entropy curves gradually decreases together with the increase of the damage in all the tests, and similar values are reached at the failure. The slope at the failure is also quite similar among the different curves, i.e., almost subhorizontal. The Kullback-Leibler Entropies also showed similarities, even though their response is more irregular. A more abrupt knee was observed between the initial and final branch of the curves. The Entropy value at the failure has very similar values for all the tests in the case of the Kullback-Leibler Entropy. 
(a)

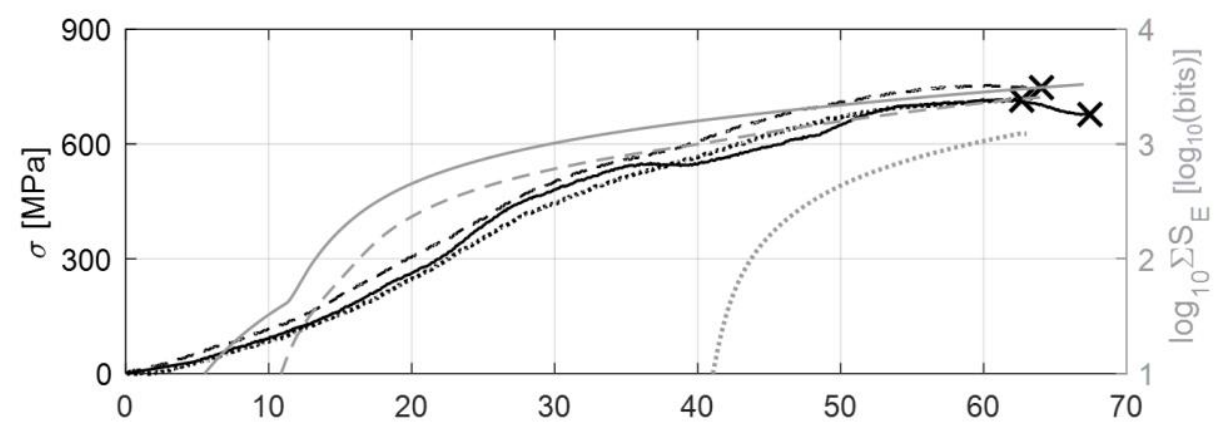

(b)

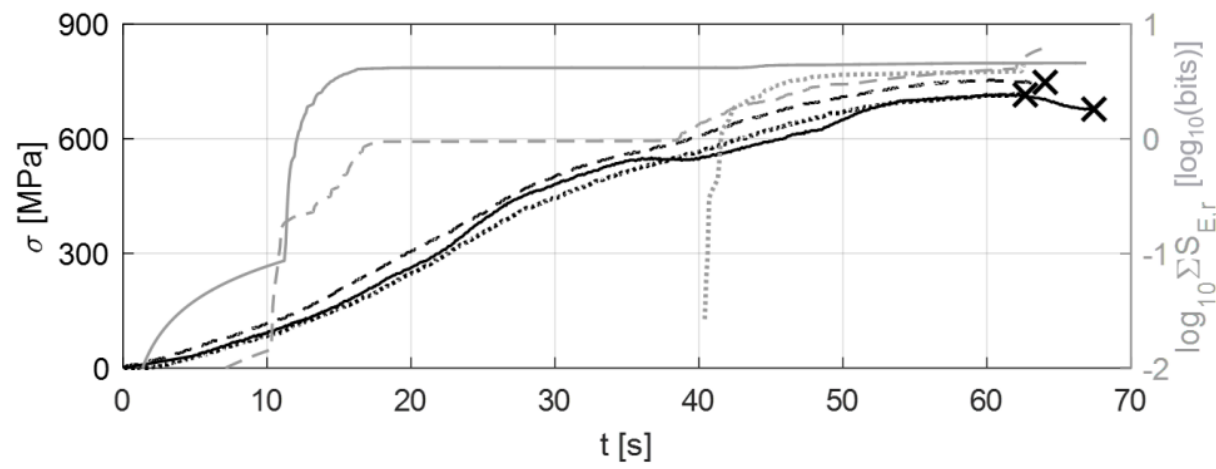

$-\sigma_{1}---\sigma_{2} \cdots \cdots \cdots \sigma_{3}-\log _{10} \Sigma \mathrm{S}_{1}---\log _{10} \Sigma \mathrm{S}_{2} \ldots \ldots \ldots \log _{10} \Sigma \mathrm{S}_{3}$

Figure 13. Engineering Stress $\sigma$ vs Time $t$ (left axis) and logarithmic cumulative AE Entropy

$\Sigma S$ vs Time $t$ (right axis) considering (a) Shannon Entropy $S_{E}$, and (b) Kullback-Leibler Entropy $S_{E, r}$.

\section{Damage criteria}

The slope of the logarithmic cumulative Shannon Entropy (i.e., $\delta\left(\log _{10} \Sigma S_{E}\right) / \delta t$ ) can be considered as a damage index. The results showed that a decrease in the Entropy slope is associated with an increase in damage, and a reduced value is correlated to the incipient failure, as it was already suggested in [26]. The value of logarithmic cumulative Kullback-Leibler can also be a quantitative descriptor of severe damage and incipient failure. Table 2 reports the statistical values (mean $\mu_{x}$, standard deviation $\sigma_{x}$, and coefficient of variation $C V_{x}$ ) of both Entropy parameters at failure for the current tests. The coefficient of variation values related to the two parameters are quite small: this indicates a relatively low data dispersion. Table 2 also reports the statistical values of the same parameters computed over Fatigue Crack Growth (FCG) tests on steel S355 and Aluminium 7075 Compact Tension (CT) specimens [26]. This aims at verifying whether the observed trends are related to the specific conditions of the current application, or they have a more holistic significance. Some studies already supported this latter hypothesis, such as the work by Kahirdeh and Khonsari [25] that focussed on cyclic 
bending testing of Aluminium and epoxy/glass specimens. In this study, the Shannon Entropy trend over the course of degradation did not (significantly) depend on the material, as well as the failure value of the Entropy. Table 2 shows that current tests and the fatigue tests on metallic CTs exhibit quite different values of $\delta\left(\log _{10} \Sigma S_{E}\right) / \delta t$ at failure. It is recalled that the testing types are extremely different between the compared tests (monotonic uniaxial tensile tests versus FCG tests), and this outcome is not surprising. However, the values of $\delta\left(\log _{10} \Sigma S_{E}\right) / \delta t$ at failure are in both cases extremely reduced, e.g., smaller than $2.0 \mathrm{E}-2 \log _{10}$ (bits) s ${ }^{-1}$. On the contrary, the values of $\log _{10} \Sigma S_{E, r}$ at failure are quite similar for the different tests, in terms of all statistical estimations. The more quantitative significance of $\log _{10} \Sigma S_{E, r}$ and the essentially constant trend over different materials was already suggested in [26].

Table 2. Statistical values of (1) slope of logarithmic cumulative Shannon Entropy $\delta\left(\log _{10} \Sigma S E\right) / \delta t$, and (2) logarithmic cumulative Kullback-Leibler $\log _{10} \Sigma S_{E, r}$ corresponding to failure for (a) current tests, and (b) fatigue tests on steel S355 and Aluminium 7075 CT specimens [26].

\begin{tabular}{|c|c|c|c|c|c|c|}
\hline & \multicolumn{3}{|c|}{$\delta\left(\log _{10} \Sigma S_{E}\right) / \delta t$ at failure } & \multicolumn{3}{|c|}{$\log _{10} \Sigma S_{E, r}$ at failure } \\
\hline & $\mu_{x}$ & $\sigma_{x}$ & $C V_{x}$ & $\mu_{x}$ & $\sigma_{x}$ & $C V_{x}$ \\
\hline & {$\left[\log _{10}(\right.$ bits $\left.) \mathrm{s}^{-1}\right]$} & {$\left[\log _{10}(\right.$ bits $\left.) \mathrm{s}^{-1}\right]$} & {$[-]$} & {$\left[\log _{10}(\right.$ bits $\left.)\right]$} & {$\left[\log _{10}(\right.$ bits $\left.)\right]$} & {$[-]$} \\
\hline Current tests & $1.09 \times 10^{-2}$ & $4.00 \times 10^{-3}$ & $3.66 \times 10^{-1}$ & $7.03 \times 10^{-1}$ & $9.15 \times 10^{-2}$ & $1.30 \times 10^{-1}$ \\
\hline Fatigue tests on & & & & & & \\
\hline steel/aluminium & $2.27 \times 10^{-4}$ & $2.57 \times 10^{-4}$ & $1.13 \times 10^{0}$ & $8.96 \times 10^{-1}$ & $1.38 \times 10^{-1}$ & $1.54 \times 10^{-1}$ \\
\hline CT [26] & & & & & & \\
\hline
\end{tabular}

The results allowed to identify potential damage criteria associated with the AE Entropy, similarly to other studies [24-26,38]. In particular, two alternative criteria identifying the incipient failure are proposed accordingly: (a) a lower bound threshold limit for $\delta\left(\log _{10} \Sigma S_{E}\right)$ / $\delta t$, and (b) an upper bound threshold limit for $\log _{10} \Sigma S_{E, r}$. The limit of the first criterion certainly depends on both testing type/features and material; however, the idea of a lower bound limit might have wider applications. The quantitative limit of the second criterion might be not significantly depending on both testing type/features and material, as suggested by past studies (Table 2). The proposed criteria might be useful for health monitoring purposes since the considered Entropy-based parameters can be univocally evaluated in real-time. The $15^{\text {th }}$ percentile limits of the experimental values of both $\delta\left(\log _{10} \Sigma S E\right) / \delta t$ and $\log _{10} \Sigma S_{E, r}$ are assumed 
for the definition of the first tentative damage criteria, which are shown in Equations (4) and (5). In particular, the first one is strictly valid for pearlitic DCI under testing conditions similar to the present application. The second one could be extended to other materials, and probably to different testing types as well.

$$
\begin{aligned}
& \frac{\delta\left(\log _{10} \Sigma S_{E}\right)}{\delta t} \leq 8.52 \times 10^{-3}\left[\log _{10}\left(\text { bits }^{-1}\right)\right] \\
& \log _{10} \Sigma S_{E, r} \geq 6.46 \times 10^{-1}\left[\log _{10}(\text { bits })\right]
\end{aligned}
$$

\section{DISCUSSION}

The elementary damaging micromechanisms identified in ferritic DCIs were also found in the pearlitic DCI, even though with different features. Such differences might be caused by the different interaction between the matrix and the nodules because of the different matrix microstructures of ferritic and pearlitic DCIs (e.g., [11]). The onset of the damage within the nodules (or at their interface with the matrix) began below the elastic limit, i.e., corresponding to applied stress ranging from 450 to $600 \mathrm{MPa}$. This proved that irreversible damage is produced within the nodules (or at their interfaces) even though the material exhibits a macroscopic elastic response. Some quantitative insights were derived from the assessment of the SEM analysis results. The matrix-nodule debonding was exhibited by a very large number of the investigated nodules ( $85 \%$ ); this occurred together with both the other mechanisms in a large number of cases (77\% of such cases). It is recalled that this mechanism was seldom observed in ferritic DCIs (e.g., occurred in a reduced percentage of the investigated nodules $[10,11])$. Onion-like mechanism was observed in a large number of nodules $(70 \%)$, whereas disgregation occurred in approximately half of the nodules (54\%). Both mechanisms were always associated with at least another mechanism. It was not identified a clear pattern for the order of the occurring mechanisms (i.e., their sequence) in individual nodules. However, few trends were observed. (1) The onion-like mechanism proceeded the disgregation in $66 \%$ of cases. (2) Disgregation occurred after at least another mechanism in $71 \%$ of cases, and it was the last one occurring in about $60 \%$ of cases. (3) The occurring of all three mechanisms in a single nodule was observed in $31 \%$ of cases. (4) Debonding was the only mechanism affecting individual nodules with the occurring of none of the others (observed in $23 \%$ of cases). 
The traditional analysis of the AE activity in pearlitic DCI allowed finding qualitative damage correlations. AEs were detected over three discontinuous stages: (1) early elastic response, (2) pre-elastic limit/yielding, and (3) pre-failure. The AE activity generated over the stage 1 might be due to the opening/closing of pre-existing cracks, or to the mechanical settlement of them under low thresholds of stress. However, the analysis of the microscope frames did not allow to verify that. Most of $\mathrm{AE}$ activity was related to stage 2, that was proven to be corresponding to the onset of the damaging micromechanisms within the graphite nodules. Elastic and preyielding damage presented AE activity with low Energy and reduced Duration. Failure was just preceded by AEs having significant Energy and large values of all features. Unfortunately, the aforementioned AE activity was quite abrupt; it did not give sensible anticipation of the failure. Therefore, the basic AE analysis was demonstrated to be not promising for structural health monitoring purposes.

The AE results related to low-carbon steel highlighted the correlation between the AEs and the damage involving the graphite nodules and their interfaces with the matrix. A copious timecontinuous AE activity was observed in the case of low-carbon steel tests; this occurred from the beginning of the test up to the failure. The exhibited acoustic patterns (continuous activity, low energy, and constant value of the AE features over the testing) might suggest that this activity is due to noise disturbance. However, it is recalled that the tests on DCIs were performed using exactly the same equipment/procedure, but the AEs detected during the DCI tests showed significantly different trends, not compatible with such noise patterns. The signals detected over the tests on low-carbon steel can be caused by noise only if it is true that the level of testing noise depends on the material significantly more than on the testing equipment. As a consequence of that, the authors consider the acoustic activity exhibited by low-carbon steel as mainly generated by the material deformation. This is also supported by the consistency between the micromechanical damage of the two tested materials and the respective $\mathrm{AE}$ activity. A relatively homogeneous material such as low-carbon steel exhibits a quite distributed pre-yielding damage, which is occurring in several locations with a relatively reduced magnitude of the energy sources. On the contrary, pre-yielding damage in DCIs essentially affect the nodules and the matrix-nodules interface; this results in a relatively reduced number of sources of energy that have a relatively large magnitude. The AE activity associated with low-carbon steel was (a) copious, (b) time-continuous, and (c) low in energy contents. On the contrary, the AE signals detected during the tests on DCIs are (a) much less copious, (b) time-discontinuous (e.g., episodic), and (c) varying their features as the damage 
increase. The acoustic activity related to the different material is perfectly consistent with the energy releases caused by the damage in this material. This represents a further confirmation on the robustness of the testing approach.

The basic AE analysis produced weak correlations that are hardly implementable to damage assessment and health monitoring purposes. The evaluation of Information Entropy of the AE data allowed to establish more quantitative damage criteria, similarly to other studies (e.g., $[24,25,38])$. Both Shannon and Kullback-Leibler Entropy formulations were correlated to the damage evolution, i.e., they identified the proceeding of the damage. The slope of logarithmic cumulative Shannon Entropy and the logarithmic cumulative Kullback-Leibler Entropy were found to be clearly correlated to the occurring of the incipient failure, as it was preliminarily found in [26] for FCG tests of metallic CTs. The failure always occurred when such parameters exceeded or fell below threshold limits; the specification of such limits (e.g., superior or inferior $15^{\text {th }}$ percentile of the experimental measurements) allowed to define applicable failure criteria. The threshold does not depend on the material if the Kullback-Leibler Entropy is considered, as it was also found in [26]. Tentative values for such limits were supplied in the paper for the investigated material to prove that the approach can be suitable for field monitoring of structures.

\section{CONCLUDING REMARKS}

The study supplied insights into the damaging micromechanisms occurring in a pearlitic DCIs. AE testing was proven to be a reliable tool for the detection of damage in DCIs. The main findings of the study are summarised below.

- The combination of multiple elementary mechanisms occurring within the graphite nodules characterises the irreversible damage evolution in fully pearlitic DCIs. Such mechanisms were already identified in ferritic DCIs, but with different trend and significance. In pearlitic DCIs the damaging micromechanisms initiate during the elastic stage of the material; on the contrary, irreversible damage only initiates at the yielding in ferritic DCIs.

- AE testing can be a reliable monitoring technique to assess both damage initiation and propagation within pearlitic DCIs. Most of the AE activity is generated during the elastic response and prior to the yielding, corresponding to the onset of the damaging 
micromechanisms within the nodules. The pattern of the AEs is clearly affected by the microstructure of the material.

- The Entropy of the AE data is clearly correlated to the damage evolution. The Entropy estimation is not affected by either analyst arbitrariness or bias for its closed-form and use of standard parameters (e.g., processing AE Counts). The real-time evaluation of the AE Entropy can be used for structural health monitoring purposes. First tentative failure criteria valid for the tested material/conditions are supplied in the paper. However, further tests should be performed to strengthen the reliability of such criteria, as well as to extend their applications to other case studies. The proposed approach should be developed furtherly in order to define health monitoring protocols/procedures applicable to (DCI) structures.

\section{ACKNOWLEDGEMENTS}

The AE testing equipment was funded by Seedling fund 2016/17, and REF 2017/18 and 2018/19 (University of Greenwich, UK).

\section{REFERENCES}

1. Iacoviello F, Cocco VD, Cavallini M. Fatigue crack propagation and overload damaging micromechanisms in a ferritic-pearlitic ductile cast iron: Stress Intensity Factors Using a new Semi-analytical Method. Fatigue \& Fracture of Engineering Materials \& Structures 2016; 39(8): 999-1011. DOI: 10.1111/ffe.12443.

2. Bellini C, Di Cocco V, Favaro G, Iacoviello F, Sorrentino L. Ductile cast irons: Microstructure influence on the fatigue initiation mechanisms. Fatigue \& Fracture of Engineering Materials \& Structures 2019; 42(9): 2172-2182. DOI: 10.1111/ffe.13100.

3. Hubner P, Schlosser H, Pusch G, Biermann H. Load history effects in ductile cast iron for wind turbine components. International Journal of Fatigue 2007; 29(9-11): 1788-1796. DOI: 10.1016/j.ijfatigue.2007.01.012.

4. Di Cocco V, Iacoviello F, Cavallini M. Damaging micromechanisms characterization of a ferritic ductile cast iron. Engineering Fracture Mechanics 2010; 77(11): 2016-2023. DOI: 10.1016/j.engfracmech.2010.03.037.

5. Iacoviello F, Di Cocco V, Rossi A, Cavallini M. Pearlitic ductile cast iron: damaging micromechanisms at crack tip. Frattura Ed Integrità Strutturale 2013; 7(25): 102-108. DOI: 10.3221/IGF-ESIS.25.15. 
6. Liu JH, Hao XY, Li GL, Liu GS. Microvoid evaluation of ferrite ductile iron under strain. Materials Letters 2002; 56(5): 748-755. DOI: 10.1016/S0167-577X(02)00608-0.

7. Guillemer-Neel C, Feaugas X, Clavel M. Mechanical behavior and damage kinetics in nodular cast iron: Part I. Damage mechanisms. Metallurgical and Materials Transactions A 2000; 31(12): 3063. DOI: 10.1007/s11661-000-0085-3.

8. Di Cocco V, Iacoviello F, Rossi A, Cavallini M, Natali S. Graphite nodules and fatigue crack propagation micromechanisms in a ferritic ductile cast iron: FATIGUE DUCTILE CAST IRONS. Fatigue \& Fracture of Engineering Materials \& Structures 2013; 36(9): 893-902. DOI: 10.1111/ffe.12056.

9. Iacoviello F, Di Cocco V, Rossi A, Cavallini M. Fatigue crack tip damaging micromechanisms in pearlitic ductile cast irons: FATIGUE CRACK TIP DAMAGING MICROMECHANISMS. Fatigue \& Fracture of Engineering Materials \& Structures 2015; 38(2): 238-245. DOI: 10.1111/ffe.12215.

10. Iacoviello F, Di Bartolomeo O, Di Cocco V, Piacente V. Damaging micromechanisms in ferritic-pearlitic ductile cast irons. Materials Science and Engineering: A 2008; 478(1-2): 181-186. DOI: 10.1016/j.msea.2007.05.110.

11. Di Cocco V, Iacoviello F, Rossi A, Cavallini M. Damaging micromechanisms characterization in a ferritic-pearlitic ductile cast iron. Frattura Ed Integrità Strutturale 2014; 8(30): 62-67. DOI: 10.3221/IGF-ESIS.30.09.

12. Unnorsson R. Hit Detection and Determination in AE Bursts. In: Sikorski W, editor. Acoustic Emission - Research and Applications, InTech; 2013. DOI: 10.5772/54754.

13. Grosse C, Ohtsu M, editors. Acoustic Emission Testing. Berlin: Springer Berlin Heidelberg; 2008. DOI: 10.1007/978-3-540-69972-9.

14. Kosnik DE, Hopwood T, Corr DJ, Thompson DO, Chimenti DE. ACOUSTIC EMISSION MONITORING FOR ASSESSMENT OF STEEL BRIDGE DETAILS, REVIEW OF PROGRESS IN QUANTITATIVE NONDESTRUCTIVE EVALUATION: Volume 30A; Volume 30B. San Diego, California, (USA): 2011. DOI: 10.1063/1.3592097.

15. Mostafapour A, Davoudi S. Analysis of leakage in high pressure pipe using acoustic emission method. Applied Acoustics 2013; 74(3): 335-342. DOI: 10.1016/j.apacoust.2012.07.012.

16. Elmaleeh MAA, Saad N, Awan M. Condition monitoring of industrial process plant using acoustic emission techniques. 2010 International Conference on Intelligent and Advanced Systems, Advanced Systems (ICIAS 2010). Kuala Lumpur, Malaysia: IEEE; 2010. DOI: 10.1109/ICIAS.2010.5716110. 
17. Al-jumaili SKJ. Damage Assessment In Complex Structures Using Acoustic Emission. 2016.

18. Beattie A. Sandia Report, Acoustic Emission Non-Destructive Testing of Structures using Source Location Techniques 2013.

19. Berkovits A, Fang D. Study of fatigue crack characteristics by acoustic emission. Engineering Fracture Mechanics 1995; 51(3): 401-416. DOI: 10.1016/00137944(94)00274-L.

20. Behnia A, Chai HK, Shiotani T. Advanced structural health monitoring of concrete structures with the aid of acoustic emission. Construction and Building Materials 2014; 65: 282-302. DOI: 10.1016/j.conbuildmat.2014.04.103.

21. Al-Jumaili SKh, Pearson MR, Holford KM, Eaton MJ, Pullin R. Acoustic emission source location in complex structures using full automatic delta T mapping technique. Mechanical Systems and Signal Processing 2016; 72-73: 513-524. DOI: 10.1016/j.ymssp.2015.11.026.

22. Schultz AE. Acoustic Emission Monitoring of a Fracture-Critical Bridge. Minnesota Department of Transportation; 2014.

23. Chen Z, Zhou X, Wang X, Dong L, Qian Y. Deployment of a Smart Structural Health Monitoring System for Long-Span Arch Bridges: A Review and a Case Study. Sensors 2017; 17(9): 2151. DOI: 10.3390/s17092151.

24. Kahirdeh A, Yun H, Modarres M. Degradation Entropy: An Acoustic Emission Based Approach to Structural Health Assessment. Structural Health Monitoring 2017, Structural Health Monitoring 2017. DEStech Publications, Inc.; 2017. DOI: $10.12783 / \mathrm{shm} 2017 / 14112$.

25. Kahirdeh A, Khonsari M. Acoustic Entropy of the Materials in the Course of Degradation. Entropy 2016; 18(8): 280. DOI: 10.3390/e18080280.

26. D’Angela D, Ercolino M. Acoustic Emission Entropy as a fracture-sensitive feature for real-time assessment of metal plates under fatigue loading. Procedia Structural Integrity 2019; 18: 570-576. DOI: 10.1016/j.prostr.2019.08.201.

27. Ercolino M, Farhidzadeh A, Salamone S, Magliulo G. Detection of onset of failure in prestressed strands by cluster analysis of acoustic emissions. Structural Monitoring and Maintenance 2015; 2(4): 339-355. DOI: 10.12989/smm.2015.2.4.339.

28. Wisner BJ, Potstada P, Perumal VI, Baxevanakis KP, Sause MGR, Kontsos A. Progressive failure monitoring and analysis in aluminium by in situ nondestructive evaluation. Fatigue 
\& Fracture of Engineering Materials \& Structures 2019; 42(9): 2133-2145. DOI: 10.1111/ffe.13088.

29. Aggelis DG, Kordatos EZ, Matikas TE. Acoustic emission for fatigue damage characterization in metal plates. Mechanics Research Communications 2011; 38(2): 106110. DOI: 10.1016/j.mechrescom.2011.01.011.

30. Vougiouklakis I, HäHner P, De Haan F, Kostopoulos V, Peteves S. Damage mode analysis of MCrAlY overlay coatings subjected to isothermal stepwise tensile testing by using in situ video imaging and acoustic emission monitoring. Fatigue \& Fracture of Engineering Materials \& Structures 2004; 27(3): 219-230. DOI: 10.1111/j.1460-2695.2004.00749.x.

31. Carpenter SH, Zhu Z. Correlation of the acoustic emission and the fracture toughness of ductile nodular cast iron. Journal of Materials Science 1991; 26(8): 2057-2062. DOI: 10.1007/BF00549167.

32. Sjögren T, Svensson IL. Studying elastic deformation behaviour of cast irons by acoustic emission. International Journal of Cast Metals Research 2005; 18(4): 249-256. DOI: $10.1179 / 136404605225023117$.

33. Kietov V, Henschel S, Krüger L. Study of dynamic crack formation in nodular cast iron using the acoustic emission technique. Engineering Fracture Mechanics 2018; 188: 5869. DOI: 10.1016/j.engfracmech.2017.07.009.

34. Kietov V, Henschel S, Krüger L. AE analysis of damage processes in cast iron and highstrength steel at different temperatures and loading rates. Engineering Fracture Mechanics 2019; 210: 320-341. DOI: 10.1016/j.engfracmech.2018.06.035.

35. Kahirdeh A, Khonsari MM. Energy dissipation in the course of the fatigue degradation: Mathematical derivation and experimental quantification. International Journal of Solids and Structures 2015; 77: 74-85. DOI: 10.1016/j.ijsolstr.2015.06.032.

36. Shannon CE. A Mathematical Theory of Communication. Bell System Technical Journal 1948; 27(3): 379-423. DOI: 10.1002/j.1538-7305.1948.tb01338.x.

37. Kullback S, Leibler RA. On Information and Sufficiency. The Annals of Mathematical Statistics 1951; 22(1): 79-86. DOI: 10.1214/aoms/1177729694.

38. Kahirdeh A, Sauerbrunn C, Yun H, Modarres M. A parametric approach to acoustic entropy estimation for assessment of fatigue damage. International Journal of Fatigue 2017; 100: 229-237. DOI: 10.1016/j.ijfatigue.2017.03.019.

39. Chai M, Zhang Z, Duan Q. A new qualitative acoustic emission parameter based on Shannon's entropy for damage monitoring. Mechanical Systems and Signal Processing 2018; 100: 617-629. DOI: 10.1016/j.ymssp.2017.08.007. 
